\title{
Inflammatory bowel disease in children and adolescents
}

\author{
Neil Chanchlani MBChB, Richard K. Russell MBChB PhD
}

Cite as: CMAJ 2019 February 11;191:E164. doi: 10.1503/cmaj.171445

\section{Diagnostic delay is common in pediatric inflammatory bowel \\ 1 disease}

The incidence of pediatric inflammatory bowel disease is rising in Canada and internationally; subtypes include Crohn disease, ulcerative colitis and unclassified. In a prospective study involving a tertiary centre cohort in Toronto, time to diagnosis was longer in cases of Crohn disease than in ulcerative colitis (6.8 v. 2.4 mo, respectively). ${ }^{1}$ For Crohn disease, diagnostic delay was associated with height impairment 1 year after presentation. ${ }^{1}$

\section{2}

\section{Extraintestinal manifestations of pediatric inflammatory bowel disease can occur before diagnosis}

Most patients will present with diarrhea (bloody in ulcerative colitis and nonbloody in Crohn disease) and pain. Extraintestinal manifestations occur in about $5 \%-10 \%$ of patients before diagnosis; arthritis and aphthous stomatitis are reported more frequently before diagnosis, and osteopenia is reported more frequently after diagnosis. ${ }^{2}$ The lifetime incidence of at least 1 extraintestinal manifestation is about $25 \%{ }^{2}$

\section{3}

\section{The presence of perianal disease can be a highly specific finding when Crohn disease is suspected}

About $15 \%$ of pediatric patients with newly diagnosed Crohn disease have perianal disease within 30 days of diagnosis, two-thirds with fistulas and abscesses. $^{3}$

Once infection has been excluded, investigation of nonbloody

diarrhea lasting longer than 2 weeks should be started in primary care ${ }^{4}$

About $80 \%$ of children with pediatric inflammatory bowel disease will have 1 or more of the following: anemia, raised erythrocyte sedimentation rate, raised C-reactive protein level, thrombocytosis and hypoalbuminemia. ${ }^{5}$ Tissue transglutaminase immunoglobulin A (IgA) and total serum IgA testing will aid investigation of celiac disease; serology will be normal in irritable bowel syndrome.

\section{Fecal calprotectin testing can aid in the diagnosis, as high levels} indicate intestinal mucosa inflammation

Calprotectin is a neutrophil protein biomarker found in stool. Once infection has been excluded, patients with diarrhea should have fecal calprotectin testing to help stratify for urgent or routine evaluation by a specialist. ${ }^{6}$ In one meta-analysis, raised fecal calprotectin levels $(>250 \mu \mathrm{g} / \mathrm{g})$ had an overall sensitivity of 0.90 and specificity of 0.85 for diagnosing pediatric inflammatory bowel disease. ${ }^{6}$

\section{References}

1. Ricciuto A, Fish JR, Tomalty DE, et al. Diagnostic delay in Canadian children with inflammatory bowel disease is more common in Crohn's disease and associated with decreased height. Arch Dis Child 2018;103:319-26.

2. Jose FA, Garnett EA, Vittinghoff E, et al. Development of extraintestinal manifestations in pediatric patients with inflammatory bowel disease. Inflamm Bowel Dis 2009; 15:63-8.

3. Keljo DJ, Markowitz J, Langton C, et al. Course and treatment of perianal disease in children newly diagnosed with Crohn's disease. Inflamm Bowel Dis 2009;15:383-7.

4. Gupta R. Diarrhea. In: Wyllie R, Hyams JS, Kay M, editors. Pediatric gastrointestinal and liver disease. 5th ed. Philadelphia: Elsevier; 2016: p. 104-14.

5. Quail MA, Russell RK, Van Limbergen JE, et al. Fecal calprotectin complements routine laboratory investigations in diagnosing childhood inflammatory bowel disease. Inflamm Bowel Dis 2009;15:756-9.

6. Degraeuwe PL, Beld MP, Ashorn M, et al. Faecal calprotectin in suspected paediatric inflammatory bowel disease. J Pediatr Gastroenterol Nutr 2015;60:339-46.

Competing interests: Neil Chanchlani reports grants from Crohn's and Colitis UK. Richard Russell reports consultation fees, research grants or honoraria from Nestlé Health Science, AbbVie, Takeda, NAPP Pharmaceuticals, Mead Johnson, Nutricia, Janssen, Therakos, Celltrion and Vifor Pharma.

This article has been peer reviewed.

Affiliations: Exeter IBD Pharmacogenetics, Royal Devon and Exeter Hospital NHS Foundation Trust (Chanchlani), Exeter, UK; Department of Pediatric Gastroenterology (Russell), The Royal Hospital for Children, Glasgow, UK

Acknowledgement: The authors thank Dr. Sally Lawrence, pediatric gastroenterologist at BC Children's Hospital, for assistance with the manuscript.

Disclaimer: Neil Chanchlani is an associate editor for CMAJ and was not involved in the editorial decision-making process for this article.

Correspondence to: Neil Chanchlani, nchanchlani@doctors.org.uk 